\title{
Effect of age related changes in chamber size, wall thickness, and heart rate on left ventricular function in normal children
}

\author{
MARTIN G ST JOHN SUTTON, * DANIEL L MARIER, PAUL J OLDERSHAW, \\ RICHARDO SACCHETTI, DEREK G GIBSON
}

From Brompton Hospital, London

SUMMARY We assessed the effects of age related changes in chamber size, wall thickness, and heart rate on left ventricular function in 78 normal children, aged $1 \frac{1}{2}$ to $12 \frac{1}{2}$ years, using computer analysis of their left ventricular echocardiograms. Left ventricular cavity size and wall thickness increased linearly with age. Left ventricular fractional shortening, percentage of wall thickening, and the ratio of end-diastolic wall thickness to cavity radius $(H / R$ ratio) did not change with age. Peak Vcf correlated with heart rate and the decrease in heart rate with age resulted in the progressive fall in peak Vcf, while peak rate of left ventricular wall thickening remained constant. The peak rate of increase in left ventricular cavity dimension in early diastole varied inversely with heart rate, but independently of cavity size, increasing throughout childhood. The peak rate of wall thinning also increased with age, correlating with wall thickness and not heart rate.

Thus, age related increases in left ventricular cavity dimension and wall thickness during the rapid growth period of childhood occurred in such a way that left ventricular architecture $(H / R$ ratio) remained unchanged. This may account for the constancy of regional and cavity systolic function. The greater dependence of diastolic cavity function on heart rate may be explained by the disproportionately greater effect of cardiac cycle length on the duration of diastole and systole.

M-mode and two dimensional echocardiography have facilitated the understanding and early recognition of complex congenital heart disease by enabling elucidation of intracardiac anatomy, sequential chamber analysis, and, more recently, determination of ventricular morphology. 1- $^{-6}$ In addition, echocardiography has been used to assess cardiac function in the newborn ${ }^{7}$ and the intrauterine growth pattern of the normal fetal heart. ${ }^{8}$ Comparatively few studies, however, have been performed upon the hearts of normally growing children. The studies that do exist have been largely concerned with measurement of chamber size, left ventricular mass, ejection fraction, and mean velocity of circumferential fibre shortening, and relating them to various computations of body surface area. ${ }^{9-17}$ Little is known, however, regarding the changes in the mechanics of myocardial contraction and relaxation that result from the progressive increase

^Present address: Hospital of the University of Pennsylvania, Philadelphia, Pennsylvania 19104, USA.

Accepted for publication 22 June 1982 in left ventricular cavity size and wall thickness that occur throughout childhood and early adolescence. In ${ }_{\stackrel{\mathbb{}}{\Phi}}$ an attempt to investigate and quantify the influence of these changes upon left ventricular regional and cavity function during this period of rapid growth, we analysed by computer the left ventricular echocardio- $\frac{\text { ? }}{3}$ grams obtained from a sufficiently large number of children, aged from $1 \frac{1}{2}$ to $12 \frac{1}{2}$ years, to circumvent the 5 impracticalities of the more ideal longitudinal study.

\section{Patients}

We obtained left ventricular echocardiograms from 78 กิ normal children aged from 19 to 149 months, of whom $\omega$ 30 were girls and 48 were boys. None had either history? or symptoms of any cardiac or indeed any other systemf disease. All children had normal blood pressure, had a clinically normal cardiovascular system on physical ${ }^{+}$ examination, and normal electrocardiograms. They were arbitrarily divided into groups by age, those below 3 years, those between 3 and 5 years, 5 and $7,7 \stackrel{\oplus}{\mathbb{Q}}$ and 9,9 and 11 , and 11 and 13 years. 


\section{Methods}

\section{ECHOCARDIOGRAPHIC RECORDINGS}

Left ventricular echocardiograms were obtained with an Ekoline 20 Ultrasonoscope using a 2.25, 3.5, or $5 \cdot 0$ $\mathrm{MHz}$ transducer with a repetition frequency of 1000 cycles/second. Recordings were made on a Cambridge Scientific Instruments multichannel strip chart recorder at a paper speed of $100 \mathrm{~mm} / \mathrm{second}$, with simultaneous electrocardiograms. Echoes from the left side of the septum, and the endocardium and epicardium of the left ventricular posterior wall were obtained at the level of the tips of the mitral valve leaflets (Fig. 1). Echocardiograms were only accepted for analysis when these echoes were clear and continuous throughout the cardiac cycle. Echocardiograms were digitised as previously described, 18 and processed by a Prime $\mathbf{4 0 0}$ computing system. Plots were made of continuous left ventricular cavity dimension and posterior wall thickness, and their respective rates of change expressed either in $\mathrm{cm} / \mathrm{s}$ or normalised by dividing by instantaneous cavity dimension or posterior wall thickness (Fig. 2). From these plots the following measurements were made:

(1) Heart rate (beats/min).

(2) Dimensions

(a) End-systolic and end-diastolic left ventricular cavity dimension $(\mathrm{cm})$ measured respectively as the point of most anterior motion of posterior wall endocardium and the onset of the $Q$ wave on the electrocardiogram.

(b) End-systolic and end-diastolic posterior wall thickness $(\mathrm{cm})$.

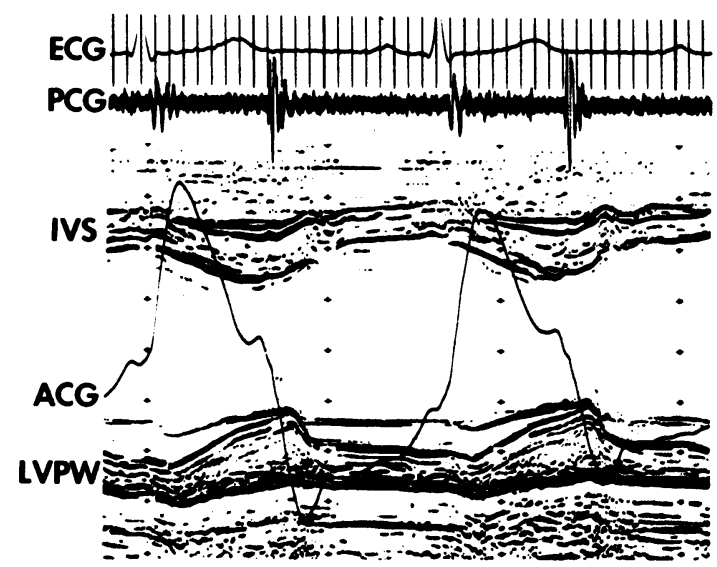

Fig. 1 Left ventricular echocardiogram from a 10 year old boy showing clear echoes from the interventricular septum (IVS) and left ventricular posterior wall (LVPW) with electrocardiogram (ECG), phonocardiogram (PCG), and apexcardiogram (ACG).
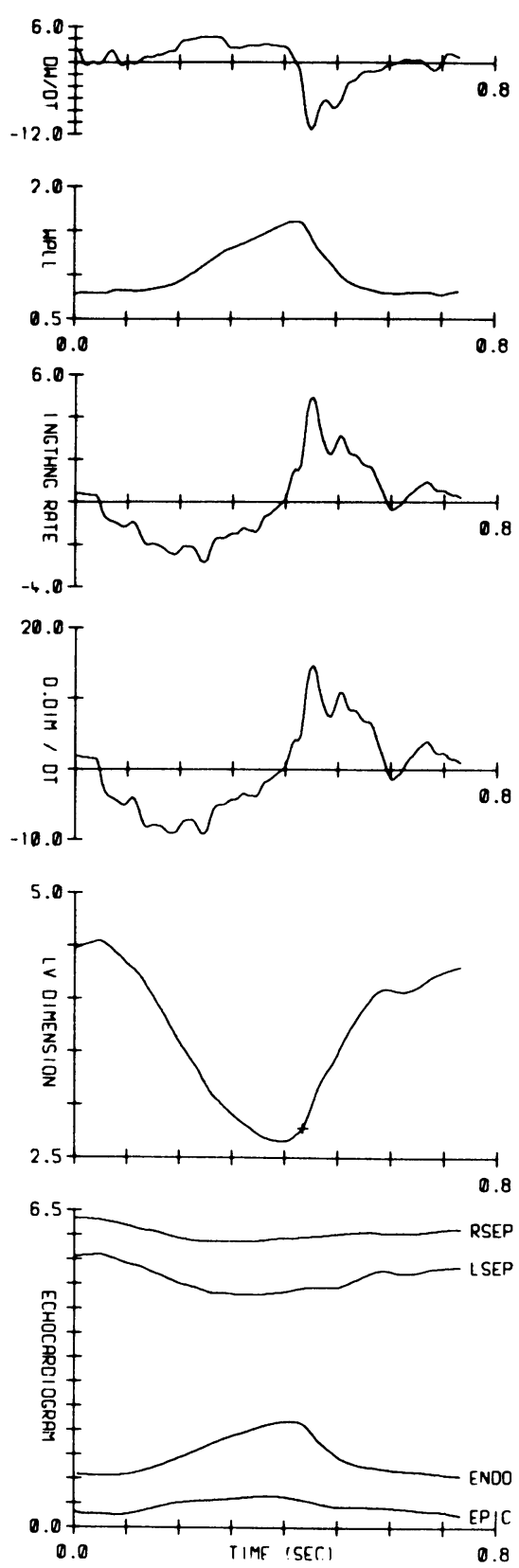

Fig. 2 Computer output of a digitised echocardiogram. At the bottom are the $X Y$ co-ordinates of the left ventricular echogram and above this in order are, instantaneous left ventricular dimension, instantaneous rate of change of left ventricular dimension (dDim/dt), left ventricular lengthening rate, continuous posterior wall thickness, and, at top, instantaneous rate of change of wall thickness. 
(c) End-diastolic relative wall thickness; that is, the ratio of posterior wall thickness to left ventricular cavity radius at end-diastole.

(3) Systolic left ventricular function

(a) Percentage left ventricular cavity shortening (\%).

(b) Peak velocity of circumferential fibre shortening, peak Vcf $/ \mathrm{s}^{-1}$.

(c) Percentage systolic thickening of the posterior left ventricular wall (\%).

(d) Peak rate of posterior left ventricular wall thickening $(\mathrm{cm} / \mathrm{s})$.

(4) Diastolic left ventricular function

(a) Peak rate of increase in left ventricular dimension $(\mathrm{cm} / \mathrm{s})$.

(b) Peak rate of posterior left ventricular wall thinning $(\mathrm{cm} / \mathrm{s})$.

In addition, the effects of each of the following: (1) age, (2) heart rate, (3) left ventricular chamber size, (4)
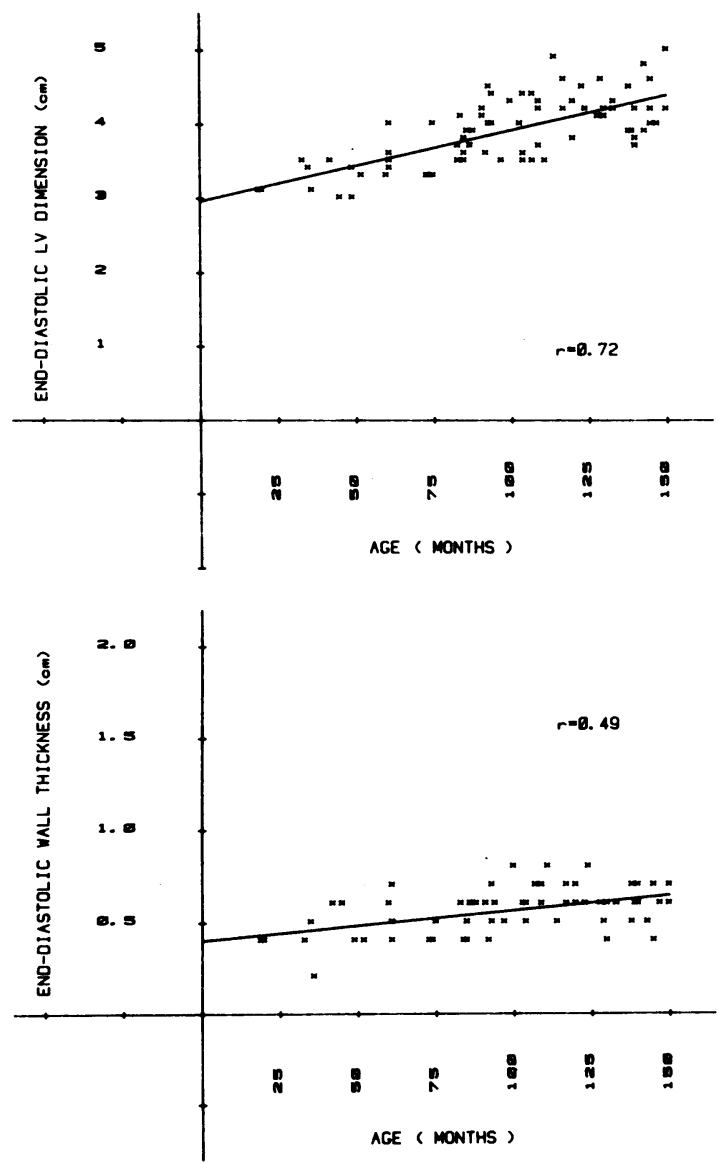

wall thickness upon systolic and diastolic global and regional left ventricular function were investigated.

\section{Results}

(1) HEART RATE

Resting heart rate varied from 60 to 119 beats $/ \mathrm{min}$, $\stackrel{\varnothing}{\varnothing}$ falling progressively with increasing age (Table 1 ).

(2) DIMENSIỌNS

End-systolic and end-diastolic left ventricular chamber dimensions increased progressively with age $(r=0.62$, o $r=0 \cdot 72$ ) (Fig. 3, Table 1). Posterior left ventricular wall thickness at end-systole and end-diastole likewise $\stackrel{+}{\infty}$ increased with age with the following correlation coefficients ( $r=0.49, r=0.53$ ) (Fig. 3, Table 1). Rela- $\omega$ tive wall thickness (that is the ratio of posterior left $\mathrm{N}$

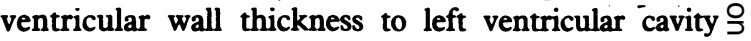
radius at end-diastole) showed no correlation with -


Fig. 3 Age related changes in left ventricular end-diastolic and end-systolic left ventricular dimension (top), and left ventricular wall thickness (bottom) in normal children. " $r$ " values represent the respective correlation coefficients. 
Table 1 Left ventricular dimensions in normal children

\begin{tabular}{|c|c|c|c|c|c|c|c|}
\hline Age & No & Heart rate/min & $\begin{array}{l}\text { End-diastolic } \\
L V \text { diameter } \\
(\mathrm{cm})\end{array}$ & $\begin{array}{l}\text { End-systolic } \\
L V \text { diameter } \\
(\mathrm{cm})\end{array}$ & $\begin{array}{l}\text { End-diastolic } \\
\text { LV wall } \\
\text { thickness } \\
\text { (cm) }\end{array}$ & $\begin{array}{l}\text { End-systolic } \\
\text { LV wall } \\
\text { thickness } \\
\text { (cm) }\end{array}$ & $\begin{array}{l}\text { End-diastolic } \\
\text { relative wall } \\
\text { thickness } \\
\text { (H/R ratio) }\end{array}$ \\
\hline $\begin{array}{l}11 / 2-3 \mathrm{y} \\
\text { Mean }=27 \mathrm{months} \\
3-5 \mathrm{y} \\
\text { Mean }=49 \mathrm{mth} \\
5-7 \mathrm{y} \\
\text { Mean }=71 \mathrm{mth} \\
7-9 \mathrm{y} \\
\text { Mean }=90 \mathrm{mth} \\
9-11 \mathrm{y} \\
\text { Mean }=119 \mathrm{mth} \\
11-13 \mathrm{y} \\
\text { Mean }=140 \mathrm{mth}\end{array}$ & $\begin{array}{r}5 \\
6 \\
11 \\
22 \\
16 \\
18\end{array}$ & $\begin{array}{r}113 \\
\pm \quad 3 \\
106 \\
\pm \quad 4 \\
94 \\
\pm \quad 6 \\
87 \\
\pm \quad 11 \\
+82 \\
\pm 7 \\
\pm \quad 9\end{array}$ & $\begin{array}{r}3.2 \\
\pm 0.2 \\
3.3 \\
\pm 0.2 \\
3.6 \\
\pm 0.3 \\
3.9 \\
\pm 0.3 \\
4.2 \\
\pm 0.4 \\
4.2 \\
\pm 0.3\end{array}$ & $\begin{array}{r}2.2 \\
\pm 0.1 \\
2.2 \\
\pm 0.2 \\
2.4 \\
\pm 0.3 \\
2.6 \\
\pm 0.3 \\
2.8 \\
\pm 0.3 \\
2.8 \\
\pm 0.3\end{array}$ & $\begin{array}{r}0.4 \\
\pm 0.1 \\
0.5 \\
\pm 0.1 \\
0.5 \\
\pm 0.1 \\
0.6 \\
\pm 0.1 \\
0.6 \\
\pm 0.1 \\
0.6 \\
\pm 0.1\end{array}$ & $\begin{array}{r}0.8 \\
\pm 0.2 \\
0.9 \\
\pm 0.2 \\
1.0 \\
\pm 0.2 \\
1.1 \\
\pm 0.2 \\
1.1 \\
\pm 0.1 \\
1.1 \\
\pm 0.1\end{array}$ & $\begin{array}{r}0.26 \\
\pm 0.02 \\
0.29 \\
\pm 0.05 \\
0.28 \\
\pm 0.05 \\
0.29 \\
\pm 0.04 \\
0.29 \\
\pm 0.05 \\
0.29 \\
\pm 0.04\end{array}$ \\
\hline
\end{tabular}

increasing age, remaining relatively constant throughout childhood (Fig. 4, Table 1), and varied over-a similar range to that of adults. ${ }^{19}$

\section{(3) SYSTOLIC LEFT VENTRICULAR FUNCTION}

Percentage left ventricular shortening remained unchanged with age throughout childhood (Fig. 5), with mean values for each age group varying from 32 to $35 \%$ (Table 2); it also varied independently of heart rate. Peak velocity of circumferential fibre shortening (peak Vcf) decreased slightly with age (Fig. 5); this reduction was associated with the fall in heart rate that occurred with increasing age (Fig. 6) since there was a positive correlation between peak Vcf and heart rate (Fig. 7). Percentage systolic wall thickening in similar fashion to fractional left ventricular shortening did not change with age or heart rate (Table 2, Fig. 5). Likewise, the peak rate of posterior wall thickening remained constant throughout childhood and, though varying over a wide range, did not correlate with heart rate or the age related increase in end-diastolic posterior wall thickness (Table 2, Fig. 7).

\section{(4) DIASTOLIC LEFT VENTRICULAR FUNCTION}

The peak rate of increase in left ventricular dimension during filling increased with age, but did not correlate with the age related increase in left ventricular chamber diameter (Table 2, Fig. 8). Since the peak rate of increase in dimension in diastole decreased with heart rate (Fig. 8), however, and heart rate decreased with age, the age related changes in peak rate of dimension increase were explained at least in part by the reduction

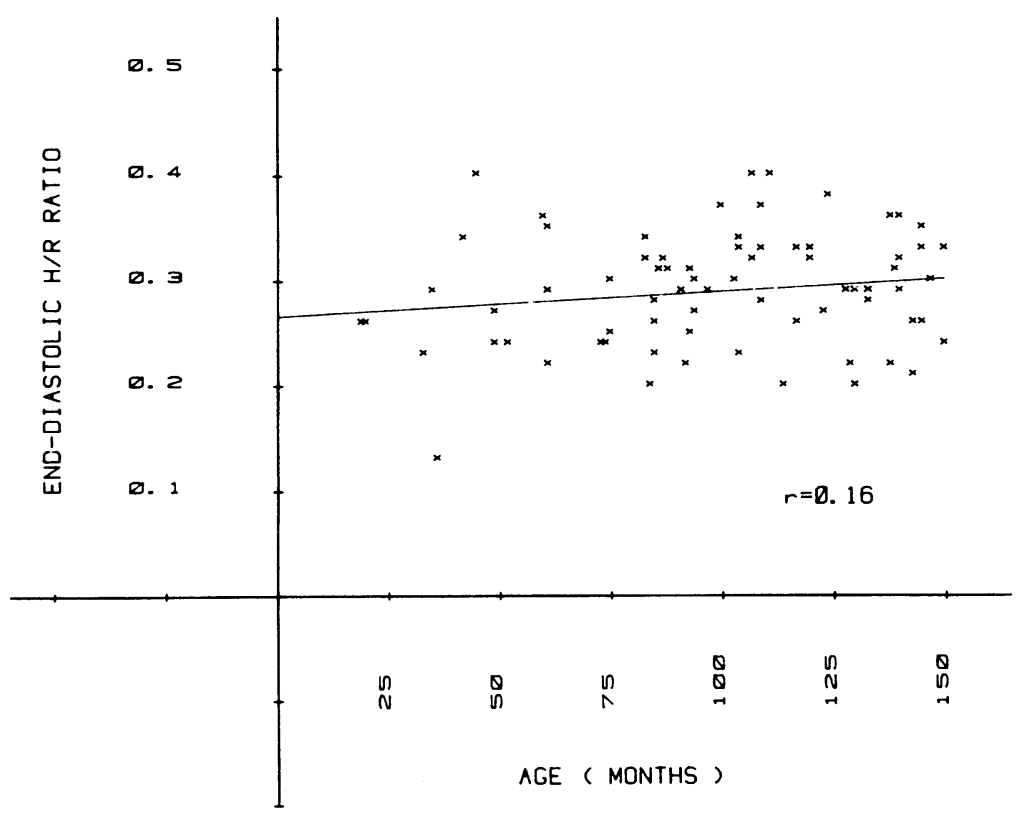

Fig. 4 Changes in left ventricular short axis architecture, expressed as the ratio of the end-diastolic wall thickness to left ventricular cavity radius $(H / R$ ratio) with age. 



Fig. 5 Left ventricular systolic function. Percentage change in left ventricular diameter (top left) and percentage change in left ventricular wall thickness (bottom left) with age. Peak Vcf decreased with age (top right), and peak rate of wall thickening remained constant (bottom left).

in heart rate. The peak rate of wall thinning, which is the major determinant of endocardial diastolic motion and therefore diastolic cavity function, increased with age (Fig. 8). This increase did not correlate with any changes in heart rate, but appeared to result from the increase in end-systolic wall thickness with age (Table 2, Fig. 9).

\section{Discussion}

Since childhood and early adolescence are characterised by rapid growth, we took the opportunity of investigating the growth pattern of the normal human left ventricle, and of assessing the physiological consequences of increasing cavity size and muscle mass on global and regional myocardial dynamics. To achieve these aims we used computer assisted analysis of the echocardiograms obtained from children from $1 \frac{1}{2}$ to 12 years of age. Ideally, the study would have been performed longitudinally, but such data acqui- $\subseteq$ sition is slow, and we hoped that the vagaries of our $\rightarrow$ cross-sectional study would be minimised by inclusion of a large number of children. We chose $M$-mode rather $N$ than two dimensional echocardiography because its much greater sampling frequency, 1000/s rather than 0 $30 / \mathrm{s}$, resulted in better definition of endo- and $\omega$ epicardium, and also allowed more accurate measurement of continuous left ventricular cavity dimension ${ }^{\circ}$ and wall thickness, and therefore their respective $\mathscr{\Phi}_{\mathscr{D}}$ instantaneous dynamics. Caution was exercised in ${ }^{+}$ recording left ventricular echocardiograms only at the $\frac{T}{0}$ level of the tips of the mitral valve leaflets, not because $\overrightarrow{\mathbb{D}}$ of any concern regarding segmental wall motion $?$

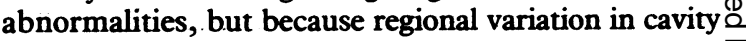




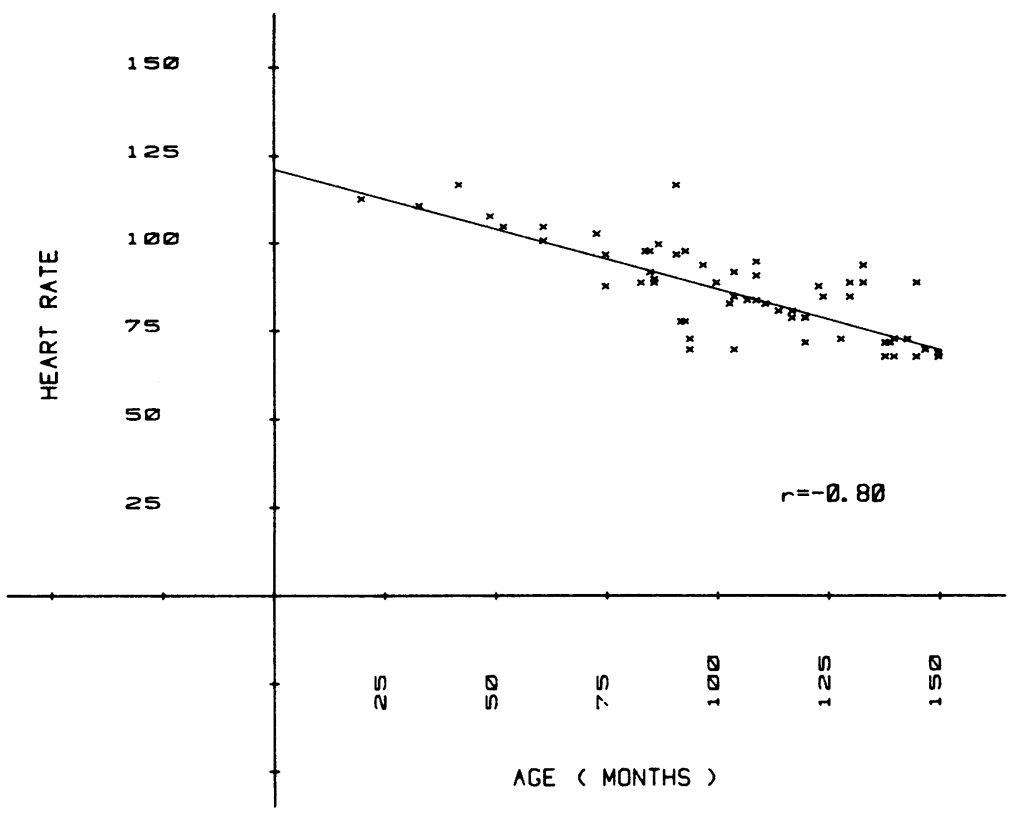

Fig. 6 Relation between resting heart rate and age in normal children.

and wall dynamics has previously been shown in the same normal ventricles at different levels along the long axis. ${ }^{20}$ Such variation has been considered to be secondary to regional differences in left ventricular architecture rather than to any alteration in the properties of the myocardial fibres themselves. ${ }^{20}$

Static measurements of left ventricular chamber diameter at end-systole and end-diastole showed a linear increase with age, concordant with previous studies, ${ }^{12-16}$ but one that occurred in such a way as to maintain percentage fractional cavity shortening virtually constant, irrespective of heart rate. Endsystolic and end-diastolic wall thicknesses also increased progressively with age and, though percentage systolic wall thickening varied widely, the mean value for each age group remained constant
(Table 2), and was unaffected either by heart rate or absolute wall thickness. Left ventricular short axis architecture, described simply in terms of ratio of wall thickness to cavity radius, or "relative wall thickness" at end-diastole, $, 21,22$ remained constant throughout childhood, varying over a similarly small range to that observed in over 600 normal subjects from the second to the ninth decade. ${ }^{19}$ The pronounced constancy of these findings during the period of rapid cardiac growth in childhood over a wide range of heart rates $(60$ to 120 beats $/ \mathrm{min}$ ), and the similarity to the normal adult left ventricle, led us to speculate that these degrees of relative wall thickness, fractional shortening, and percentage wall thickening were possibly the most mechanically advantageous. Moreover, they may have been involved not only in modelling. or autoregulation

Table 2 Left ventricular systolic and diastolic function in normal children

\begin{tabular}{|c|c|c|c|c|c|c|c|c|}
\hline Age & No & Heart rate/min & $\begin{array}{l}\text { Fractional } \\
L V \text { shortening } \\
(\%)\end{array}$ & $\underset{\left(s^{-1}\right)}{\text { Peak } V c f}$ & $\begin{array}{l}\text { Peak rate of } \\
\mathrm{LV} \mathrm{fulling} \\
(\mathrm{cm} / \mathrm{s})\end{array}$ & $\begin{array}{l}\text { \% systolic wall } \\
\text { thickening (\%) }\end{array}$ & $\begin{array}{l}\text { Peak rate of } \\
\text { systolic wall } \\
\text { thickening }(\mathrm{cm} / \mathrm{s})\end{array}$ & $\begin{array}{l}\text { Peak rate of } \\
\text { diastolic wall } \\
\text { thinning }(\mathrm{cm} / \mathrm{s})\end{array}$ \\
\hline \multirow{6}{*}{$\begin{array}{l}11 / 2-3 \mathrm{y} \\
\text { Mean }=27 \mathrm{mth} \\
3-5 \mathrm{y} \\
\text { Mean }=49 \mathrm{mth} \\
5-7 \mathrm{y} \\
\text { Mean }=71 \mathrm{mth} \\
7-9 \mathrm{y} \\
\text { Mean }=90 \mathrm{mth} \\
9-11 \mathrm{y} \\
\text { Mean }=119 \mathrm{mth} \\
11-13 \mathrm{y} \\
\text { Mean }=140 \mathrm{mth}\end{array}$} & 5 & \multirow{6}{*}{$\begin{array}{r}113 \\
+\quad 3 \\
106 \\
+\quad 4 \\
94 \\
+\quad 6 \\
87 \\
+11 \\
82 \\
\pm \quad 7 \\
+\quad 73\end{array}$} & $32 \pm 7$ & $2.5 \pm 0.4$ & $9 \cdot 2 \pm 1 \cdot 3$ & $113 \pm 24$ & $2.9 \pm 1.0$ & $5 \cdot 0 \pm 1.4$ \\
\hline & 6 & & $34 \pm 3$ & $2.5 \pm 0.4$ & $11 \cdot 2 \pm 3 \cdot 7$ & $107 \pm 39$ & $3 \cdot 2 \pm 1 \cdot 2$ & $8.6 \pm 2 \cdot 0$ \\
\hline & 11 & & $33 \pm 4$ & $2 \cdot 2 \pm 0.4$ & $11.6 \pm 1.9$ & $98 \pm 29$ & $3.4 \pm 1.0$ & $8 \cdot 0 \pm 1 \cdot 4$ \\
\hline & 22 & & $34 \pm 4$ & $2 \cdot 3 \pm 0.4$ & $12.5 \pm 3.5$ & $87 \pm 25$ & $3 \cdot 3 \pm 1.0$ & $8.9 \pm 2.2$ \\
\hline & 16 & & $34 \pm 4$ & $2 \cdot 2 \pm 0.4$ & $14 \cdot 1 \pm 2 \cdot 7$ & $82 \pm 27$ & $3 \cdot 4 \pm 1 \cdot 1$ & $9 \cdot 6 \pm 2.5$ \\
\hline & 18 & & $34 \pm 4$ & $2.0 \pm 0.4$ & $14 \cdot 1 \pm 2 \cdot 3$ & $93 \pm 24$ & $3.5 \pm 0.7$ & $9 \cdot 3 \pm 2.0$ \\
\hline
\end{tabular}



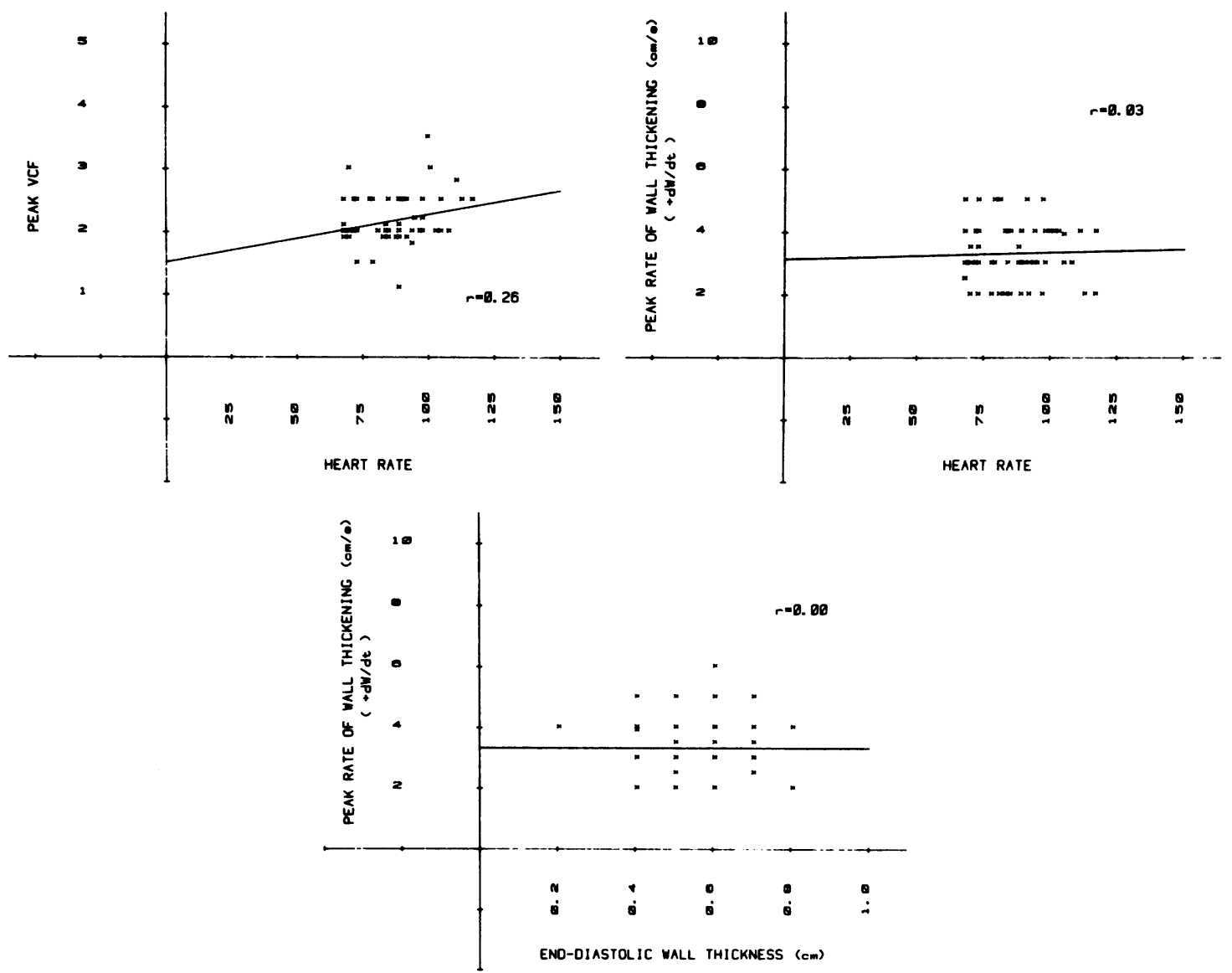

Fig. 7 Peak Vcf increased with heart rate (top left) though the correlation was weak $(r=0 \cdot 36)$. Peak rate of wall thickening did not correlate either with heart rate (top right) or end-diastolic wall thickness (bottom).

of cardiac architecture, but also in the resultant left ventricular functional capacity, though which was cause and which was effect was unresolved.

Assessment of left ventricular cavity dynamic function by computer processing of left ventricular echograms is a simple expression of the changes and rates of change in endocardial position. The major determinants of endocardial motion during cavity ejection and filling are the respective velocities of contraction and relaxation of the myocardium and the orientation of muscle fibres surrounding the enclosed left ventricular cavity. In the normal human left ventricle, because of its ellipsoidal configuration and oblique muscle fibre arrangement, cavity filling and emptying are achieved more by changes in the short axis than the long axis, and it is the short axis that is recorded from cardiac cycle to cardiac cycle with $M$ mode echocardiography. Computer analysis of these digitised recordings provides plots of continuous cavity dimension and wall thickness from which their respective systolic and diastolic instantaneous dynamics were derived. We used the peak velocity of $O$ circumferential fibre shortening (peak Vcf) to assess $\rightarrow$ systolic cavity function, and the peak rate of increase in left ventricular diameter to assess diastolic cavity $N$ function. We selected these two peak measurements of left ventricular cavity function because (1) they have $O$ been previously validated with left ventriculography $18 \mathrm{\omega}$ and (2) because the variation in heart rate among these children precluded comparison of any "QRS-timegated" rates of change of left ventricular dimension.

Peak Vcf is the normalised rate of left ventricular shortening, obtained by dividing the peak rate of change in left ventricular diameter by its own instantaneous cavity dimension, so as to minimise the effect of heart size per se on the peak rate of left ventricular 



Fig. 8 Left ventricular diastolic function: peak rate of increase in left ventricular dimension $+d D / d t$ during early diastolic filling increased with age (top left), and heart rate (bottom left). Peak rate of wall thinning increased with age (top right) but varied independently of heart rate (bottom right).

shortening, and so that ventricles of varying sizes could be compared. Peak Vcf decreased slightly with increasing age and this reduction was partly the result of the age related fall in heart rate (Fig. 6) since peak Vcf increased with tachycardia (Fig. 7). Regional systolic dynamic function assessed in terms of the peak rate of systolic wall thickening changed minimally with age, heart rate, or age related increase in end-diastolic wall thickness. Since the rate of systolic wall thickening determined systolic cavity function by its direct effect upon endocardial motion, its lack of change with age accounted for the minimal changes in peak Vcf throughout childhood beyond those resulting from heart rate.

The changes in diastolic cavity dynamics were considerably different from those of systolic dynamics, in that the peak rate of increase in left ventricular dimension increased progressively with age, and this was not determined by end-systolic left ventricular chamber size. Peak rate of dimension increase, in contrast to peak Vcf, varied inversely with heart rate, decreasing significantly with tachycardia over the range of resting heart rates observed in this study. Peak rate of wall thinning increased with age. This change in peak rate of wall thinning was unrelated to any change in heart rate, but was correlated with the progressive increase in end-systolic wall thickness with age, so that the thicker the wall, the faster the peak velocity of wall thinning. When the peak rates of wall thinning were normalised to unit wall thickness, the relation with age was abolished. Thus, it was the increase in peak wall thinning rate secondary to the increase in wall thick- 

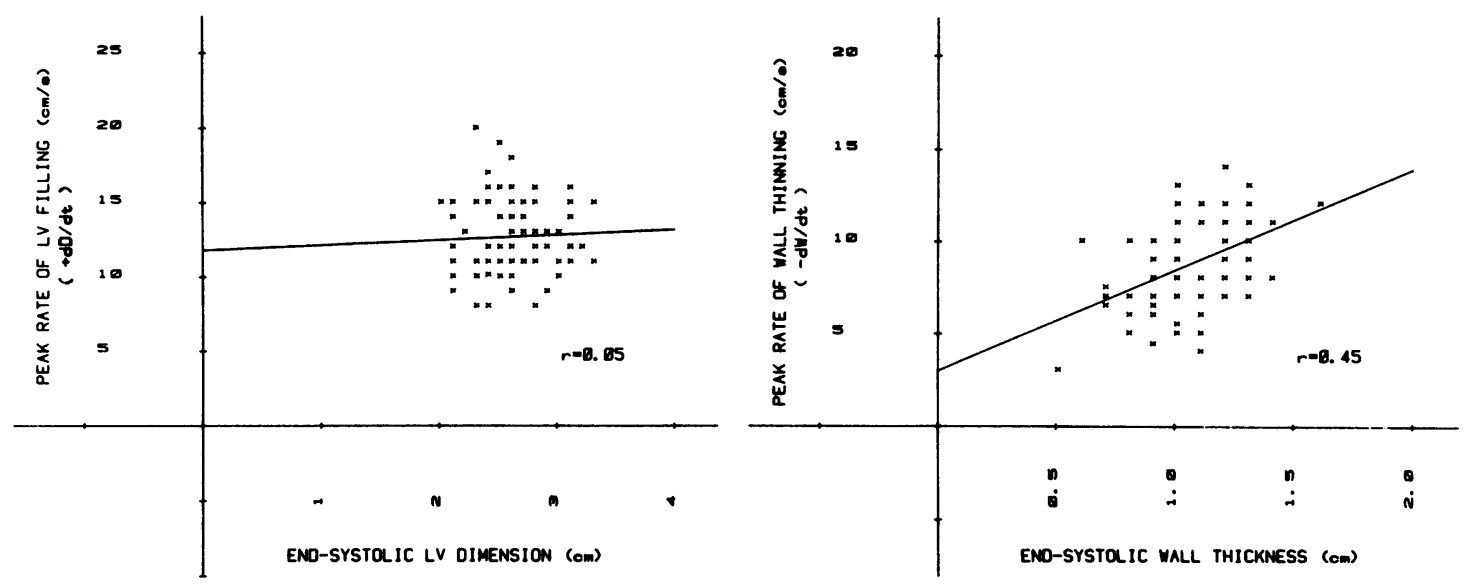

Fig. 9 Peak rate of increase in left ventricular diameter (left ventricular filling) did not correlate with end-systolic left ventricular dimension (left), but peak rate of wall thinning increased with increase in end-systolic wall thickness (right).

ness, and not the change in heart rate that resulted in the progressive increase in the peak rate of left ventricular cavity filling with age.

Throughout childhood, systolic and diastolic left ventricular cavity dynamics, when expressed in terms of peak Vcf and peak rate of dimension increase respectively, were independent of chamber size, but not of changes in heart rate. Diastolic cavity function, as might have been expected, was more sensitive to changes in heart rate than systolic function over the range of resting heart rates observed, presumably because of the disproportionately greater shortening of the diastolic filling period than the systolic ejection period, with shortening of the cardiac cycle length.

We thought initially that the absence of any correlation between peak rates of systolic wall thickening and either age or wall thickness, compared with the contrastingly strong relation between peak rate of wall thinning and age related increase in wall thickness, might have resulted from a relatively greater increase in end-systolic than end-diastolic wall thickness with age. On closer scrutiny, however, the percentage increases in end-systolic and end-diastolic wall thicknesses over the age range from $1 \frac{1}{2}$ to $12 \frac{1}{2}$ years were similar (approximately 50\%). Both peak rates of systolic wall thickening and diastolic wall thinning when normalised to unit wall thickness were almost constant over a period of rapid cardiac growth during which left ventricular chamber size and wall thickness increased by more than $50 \%$. This remarkable constancy indicated to us that these measurements were more likely discriptors of myocardial function per se than manifestations of cavity ejection and filling, concordant with previous suggestions. ${ }^{22-24}$
We conclude that during the period of rapid growth in childhood and early adolescence there was a progressive increase in left ventricular chamber diameter and this was accompanied by a concomitant increase in the wall thickness in such a way that left ventricular architecture remained unchanged. This fixed relation between wall thickness and chamber radius may account for the constancy particularly of systolic cavity and regional myocardial function with age. The greater variability in diastolic than systolic left ventricular dynamics may be explained by the disproportionately greater effect of age related changes in heart rate on diastole than systole. Thus the consequences of age related increases in left ventricular chamber diameter, wall thickness, and muscle mass upon regional and cavity function were minimised by maintaining left ventricular architecture constant.

\section{References}

1 Lundström NR. Ultrasoundcardiographic studies of the mitral valve region in young infants with mitral atresia, mitral stenosis, hypoplasia of the left ventricle, and cor triatriatum. Circulation 1972; 45: 324-34.

2 Chesler E, Joffe HS, Vecht R, Beck W, Schrire V. Ultrasound cardiography in single ventricle, and the hypoplastic left and right heart syndromes. Circulation 1970; 42: 123-9.

3 Sahn DJ, Vaucher Y, Williams DE, Allen HD, Goldberg SJ, Friedman WF. Echocardiographic detection of large left to right shunts and cardiomyopathies in infants and $\stackrel{?}{+}$ children. Am f Cardiol 1976; 38: 73-9.

4 Johnson GL, Meyer RA, Schwartz DC, Korfhagen J, Kaplan S. Left ventricular function by echocardiography $\mathbb{\Phi}$ in children with fixed aortic stenosis. Am J Cardiol 1976; 38: 611-9. 
5 Goldberg SJ, Allen HD, Sahn DJ. Pediatric and adolescent echocardiography: a handbook. Chicago: Yearbook Medical Publishers, 1975.

6 Hagler DJ, Tajik AJ, Seward JB, Mair DD, Ritter DG. Wide-angle two-dimensional echocardiographic criteria for ventricular morphology (abstract). Am F Cardiol 1980; 45: 466.

7 St John Sutton MG, Hagler DJ, Tajik AJ, et al. Cardiac function in the normal newborn. Additional information by computer analysis of the $M$-mode echocardiogram. Circulation 1978; 57: 1198-204.

8 Sahn DJ, Lange LW, Allen HD, et al. Quantitative realtime cross-sectional echocardiography in the developing normal human fetus and newborn. Circulation 1980; 62: 588-97.

9 Kugler JD. Instantaneous rates of left ventricular wall motion in infants and children. Pediatr Cardiol 1979; 1: 15-21.

10 Björkhem G. Echocardiographic assessment of left ventricular function. Investigation of infants, children and teenagers without heart disease. Eur $\mathcal{F}$ Cardiol 1977; 6: 83-98.

11 Friedman MJ, Sahn DJ, Burris HA, Allen HD, Goldberg SJ. Computerised echocardiographic analysis to detect abnormal systolic and diastolic left ventricular function in children with aortic stenosis. Am $\mathcal{F}$ Cardiol 1979; 44: 478-86.

12 Lundstrum NR. Clinical applications of echocardiography in infants and children. 1 . Investigation of infants and children without heart disease. Acta Paediatr Scand 1974; 63: 23-32.

13 Gutgesell HP, Paquet M, Duff DF, McNamara DG. Evaluation of left ventricular size and function by echocardiography. Results in normal children. Circulation 1977 ; 56: 457-62.

14 Rogé CLL, Silverman NH, Hart PA, Ray RM. Cardiac structure, growth pattern determined by echocardiography. Circulation 1978; 57: 285-90.
15 Henry WL, Ware J, Gardin JM, Hepner SI, McKay J, Weiner M. Echocardiographic measurements in normal subjects. Growth-related changes that occur between infancy and early childhood. Circulation 1978; 57: 278-85.

16 Henry WL, Gardin JM, Ware JH. Echocardiographic measurements in normal subjects from infancy to old age. Circulation 1980; 62: 1054-61.

17 Hunter S, Mortera C, Sheridan D, Tynan M. Age related changes in left ventricular size and performance, an echocardiographic study (abstract). Circulation 1975; 52, suppl II: 198.

18 Gibson DG, Brown DJ. Measurement of instantaneous left ventricular dimension and filling rate in man using echocardiography. Br Heart f 1973; 35: 1141-9.

19 St John Sutton MG, Reichek N, Lovett JL, Kastor JA, Giuliani ER. Effects of age, body size, and blood pressure on the normal human left ventricle (abstract). Circulation $1981 ; 62$, suppl III: 305.

20 Shapiro E, Marier DL, St John Sutton MG, Gibson DG. Regional non-uniformity of wall dynamics in normal left ventricle. Br Heart f 1981; 45: 264-70.

21 Gaasch WH. Left ventricular radius to wall thickness ratio. Am F Cardiol 1979; 43: 1189-94.

22 Ford LE. Heart size. Circ Res 1976; 39: 291-303.

23 Gibson DG, Traill TA, Brown DG. Changes in left ventricular free wall thickness in patients with ischaemic heart disease. $\mathrm{Br}$ Heart $\mathrm{f}$ 1977; 39: 1312-8.

24 Gibson DG, Greenbaum D, Marier DL, Brown DJ. Clinical significance of early diastolic changes in left ventricular wall thickness. Eur Heart $\mathcal{F}$ 1980; suppl A: 157.

Requests for reprints to Dr M G St John Sutton, Division of Cardiology, 959 Gates Building, Hospital of the University of Pennsylvania, 3400 Spruce Street, Philadelphia, Pennsylvania 19104, USA. 